\title{
ENTRE DISCIPLINAS PEDAGÓGICAS E DISCIPLINAS \\ ESPECÍFICAS: A FORMAÇÃO DE PROFESSORES E A QUESTÃO DO \\ ESTÁGIO SUPERVISIONADO EM UM CURSO DE LICENCIATURA \\ INTEGRADA
}

\section{Tacita Ansanello Ramos \\ Faculdade de Educação \\ Universidade de Campinas}

Maria Inês Petrucci Rosa

Faculdade de Educação

Universidade de Campinas

\begin{abstract}
Resumo
As disciplinas pedagógicas e específicas, especialmente nos cursos de formação de professores, historicamente vêm sendo marcadas por disputas e relações de poder no que concerne à constituição dos currículos dos cursos de licenciatura. Nessa perspectiva, esse artigo pretende problematizar o aumento da carga horária dos estágios supervisionados, em decorrência das Diretrizes Curriculares Nacionais para a Formação de Professores da Educação Básica - DCNFP (PARECER CNE/CP 9/2001), e as possibilidades que esse aumento tem significado para o afastamento da antiga concepção de formação de professores, que ficou caracterizada como modelo $3+1$, para a menor diferenciação entre disciplinas específicas e disciplinas pedagógicas, deixando de lado a antiga concepção da licenciatura como algo de responsabilidade exclusiva da Faculdade de Educação e para tentativas de construção de um currículo mais integrado. Para isso, será trazido para análise parte de um estudo genealógico realizado sobre o curso de Licenciatura Integrada em Química/Física da UNICAMP, através das narrativas, numa perspectiva benjaminiana, de 10 professores da Faculdade de Educação (FE), do Instituto de Física (IFGW) e do Instituto de Química (IQ) dessa universidade, que participaram da constituição curricular do curso em questão.
\end{abstract}

Palavras-chave: Disciplinas Pedagógicas e Específicas; Estágio Supervisionado; Formação de Professores.

Olh@res, Guarulhos, v. 1, n1, p. 207-238, maio. 2013. 


\title{
BETWEEN PEDAGOGICAL SUBJECTS AND \\ SPECIFICS SUBJECTS: THE TEACHERS' \\ FORMATION AND THE QUESTION ABOUT \\ SUPERVISED TRAINING IN AN INTEGRATED \\ GRADUATION COURSE
}

\begin{abstract}
The pedagogical and specifics subjects, especially in teachers' formation courses, historically have been marked by disputes and power relations in regard to the constitution of the teachers' formation curriculum. In this perspective, this paper intends to discuss the increased workload of supervised training, due to the National Curriculum Guidelines for Teachers' Formation of Basic Education (CNE / CP 9/2001), and the possibilities that this increase has meant for the removal of the old conception of teachers' formation, which was characterized as a model $3+1$, to lesser differentiation between specific subjects and pedagogical subjects, leaving aside the old notion of teachers' formation course as something solely the responsibility of the Faculty of Education and for attempts to build a more integrated curriculum. This will be brought to the analysis part of a genealogical study conducted over the course of the Integrated Graduation in Chemistry/Physics from UNICAMP, through narratives, in a Benjamin perspective, of 10 professors of the Faculty of Education (FE), the Institute of Physics (IFGW) and the Institute of Chemistry (IQ) of this university, who participated of the establishment of curricular course in question.
\end{abstract}

Keywords: Pedagogical and Specifics Subjects; Supervised Training; Teachers' Formation. 
Entre disciplinas pedagógicas e disciplinas específicas: a formação de professores e a questão do estágio

supervisionado em um curso de licenciatura integrada

Entre disciplinas pedagógicas e disciplinas específicas: a formação de professores e a questão dos estágios supervisionados

A palavra currículo, do latim - "scurrere" - que significa correr, passou a ser utilizada no final do século XVI para designar o conjunto de assuntos estudados pelos alunos ao longo de um curso. Segundo Goodson (1995), essa origem encontra-se associada ao emergir de uma preocupação com a sequência da escolarização.

Embora o currículo tenha sido inicialmente definido como um conjunto de disciplinas, programas de estudos e conteúdos prédeterminados a serem trabalhados com os alunos, sua definição não pode se basear somente nisso. Segundo Silva (2003, p. 14), "aquilo que o currículo é depende precisamente da forma como ele é definido pelos diferentes autores e teorias.".

No contexto da cultura, o currículo pode ser entendido como o conjunto de documentos, normas, regulamentos, princípios, conteúdos e práticas que orientam as ações educativas. Segundo Lopes (2008), o currículo é definido como um híbrido de vozes recontextualizadas, tendo a participação de textos oficiais e não-oficiais. Desta forma, o currículo é constituído pelo contexto histórico em que ele encontra-se inserido, como também pelas práticas dos professores e da própria instituição de ensino.

O currículo não é um processo pronto e acabado, tampouco resultado de evoluções contínuas. Sua história é marcada por grandes descontinuidades e rupturas, além de conflitos e lutas entre diferentes tradições e concepções sociais pelo o que deveria ser ensinado, como deveria ser ensinado e o porquê, em determinado momento histórico, daquilo ser ensinado. (RAMOS, 2008)

\footnotetext{
Nessa perspectiva, o currículo deve ser visto não apenas como a expressão ou a representação ou o reflexo de interesses sociais determinados, mas também como produzindo identidades e subjetividades sociais determinadas. O currículo não apenas representa, ele faz. É preciso reconhecer que a inclusão ou exclusão no currículo tem conexões com a inclusão ou exclusão na sociedade. (GOODSON, 1995, p. 10)
}

Olh@res, Guarulhos, v. 1, n1, p. 207-238, maio. 2013. 
Nas instituições educativas, em especial nas escolares, a constituição do currículo muitas vezes foi marcada por mudanças no sentido de atender às necessidades sociais de uma determinada época, uma vez que no currículo é possível encontrar a expressão de como a sociedade vem sendo estabelecida e, com isso, que profissional procura-se formar para atender às suas necessidades. (RAMOS, 2008)

Sendo assim, a construção curricular de um curso não pode ser vista como um processo neutro e ingênuo, mas como resultado de um processo complexo de relações de poder e de interesses em um determinado contexto sócio-histórico. É preciso perceber que a construção do currículo não é um processo lógico e imparcial no qual se determina o que é considerado melhor para ser ensinado. (GOODSON, 1995)

Dentro desse contexto, na história moderna do currículo escolar, a noção de disciplina surgiu como uma forma de controlar, ordenar os conhecimentos ensinados às pessoas e passados de geração para geração, não sendo mera transposição da ciência pura a que ela corresponde, estando ligada a forças e interesses sociais sobre aquele conhecimento em determinado período. (RAMOS, 2008)

Segundo Goodson (1995), uma disciplina pode ser entendida como uma maneira de organizar e delimitar os territórios de trabalho, pesquisa e ensino, oferecendo cada uma delas uma imagem particular da realidade, sob um determinado ângulo de visão específico.

No entanto, embora manifestem certa continuidade ao longo de sua existência, as disciplinas não são corpos eternos e imutáveis e não podem ser vistas como conhecimentos fixos e incontestáveis, mas como conjuntos de conhecimentos frutos de determinados acontecimentos históricos que estão em constante transformação, construção, desconstrução e renovação.

De acordo com Lopes (2005), a disciplina escolar é uma construção histórica e uma tecnologia de organização curricular constituída a partir de discursos híbridos e recontextualizados. Uma vez que a disciplina escolar é tecida em determinados contextos sociais e poli-

Olh@res, Guarulhos, v. 1, n1, p. 207-238, maio. 2013. 
ticos, "as disciplinas escolares respondem a objetivos sociais da educação, segundo rumos de institucionalização próprios." (LOPES e MACEDO, 2002, p. 80).

Lopes e Macedo (2002) ainda ponderam que, mesmo quando é possível, em uma matriz disciplinar algum tipo de integração, como a criação de disciplinas integradas ou articulação de disciplinas isoladas, essa ocorre sob a manutenção de uma matriz disciplinar, que resulta na transformação desta integração entre as disciplinas em uma nova disciplina. Historicamente, a organização do conhecimento escolar tem tido sua base na disciplinaridade.

(...) a organização disciplinar é a que tem sido hegemônica na história do currículo. A despeito de todas as tentativas de organização de um currículo nãodisciplinar, é por intermédio das disciplinas que o conhecimento vem sendo prioritariamente transmitido nas escolas. (LOPES e MACEDO, 2002, p. 73-74)

Segundo Lopes e Macedo (2002), a disciplina escolar é uma instituição social necessária, pois estabelece os conhecimentos legitimados a serem ensinados, organizam o trabalho escolar, os exames escolares, os métodos de ensino e a própria formação de professores.

Em um artigo que se propõe a trabalhar com as tensões presentes em práticas curriculares interdisciplinares entre professores da escola básica, Rosa (2007) mostra como a marcação disciplinar é fortemente instalada no currículo da educação básica brasileira a partir da materialização de três dimensões: o livro didático, a grade de horários e as aulas ministradas separadamente por professores especializados.

Essa especialização - traço mais forte da ciência moderna - estabiliza na escola básica o que Rosa (2007) denomina por currículoloteamento, o qual "estabelece uma lógica de controle das relações de trabalho e dos processos de conhecimento no contexto da cultura escolar" (p. 55).

Olh@res, Guarulhos, v. 1, n1, p. 207-238, maio. 2013. 
Nesse loteamento, onde se inventa vencedores e perdedores, disciplinas que são mais merecedoras ou não de tempo e espaço dentro do currículo, ser professor de uma determinada disciplina:

(...) é uma condição que vai além da dimensão epistemológica ou cognitiva é carregar também consigo as práticas advindas do campo simbólico configurado nas relações de poder presentes na sua comunidade acadêmica de referência. (ROSA, 2007, p. 58)

$\mathrm{Na}$ constituição dos cursos de licenciatura, as disputas entre disciplinas específicas e disciplinas pedagógicas na busca por lugar, status e poder dentro desses currículos é algo que historicamente vem configurando a constituição curricular dos cursos de formação de professores.

Nessa perspectiva, ao pensarmos na configuração de um currículo integrado de formação de professores, não podemos perder de vista as relações de poder existentes entre as disciplinas pedagógicas e específicas. Se esse currículo for pensado na perspectiva de uma integração curricular, essas relações também estarão presentes na disputa existente entre essas disciplinas por maior poder, maior visibilidade e maior espaço dentro desse currículo.

Quando professore(a)s de... (química, física, biologia, geografia, história, etc...) se envolvem em processos de tradução (Hall, 2003a), jogando suas culturas com as culturas do(s) Outro(s), há conhecimentos que são preteridos, enquanto outros são preferidos na configuração das práticas escolares chamadas de ações interdisciplinares. (ROSA, 2007, p. 61)

Segundo Santomé (1998), um dos principais obstáculos que faz com que propostas de integração curricular não sejam bem-sucedidas dentro das universidades é a grande fragmentação das mesmas em institutos e departamentos.

Uma situação que, a meu ver, funciona como um obstáculo às propostas de interdisciplinaridade é a grande fragmentação das Universidades em Faculdades e das Escolas Universitárias em especialidades. Cada especialidade trata de possuir uma faculdade exclusiva. Deste modo, cada vez mais as áreas do conhecimento ficam mais isoladas, criando-se um caldo de cultura favorável ao aparecimento de mais subespecialidades dentro de cada disciplina que integra cada área do conhecimento. (SANTOMÉ, 1998, p. 81)

Em um projeto de currículo integrado, os jogos de poder e embates entre as disciplinas na busca por maior status e território dentro de determinado currículo faz surgir a grande fragmentação das áreas do

Olh@res, Guarulhos, v. 1, n1, p. 207-238, maio. 2013. 
Entre disciplinas pedagógicas e disciplinas específicas: a formação de professores e a questão do estágio supervisionado em um curso de licenciatura integrada

conhecimento e a grande especialização que há na formação dos alunos nas universidades.

Essa assertiva também pode ser estendida para os cursos de licenciatura, ainda mais quando esses são criados na perspectiva da formação integrada de professores. Na vivência curricular desses cursos de licenciatura é possível experienciar situações onde as disciplinas pedagógicas ministradas na Faculdade de Educação são vistas como de menor importância por alunos e até mesmo professores, quando comparadas com as disciplinas específicas. Tais rivalidades e hierarquizações exemplificam bem as relações de podersaber existentes entre as disciplinas e comunidades epistêmicas dentro de um projeto curricular.

Muito embora essas relações de poder existam, uma vez que "uma sociedade sem relações de poder só pode ser uma abstração" (FOUCAULT, 1995, p. 245), e tornem todo o processo de construção curricular de um curso muito mais rico, a forte marca disciplinar colocada pelos diferentes grupos de especialistas na busca por status, território e uma hierarquização extrema dentro desse currículo podem representar o fracasso de projetos pensados na perspectiva da integração curricular, reforçando a disciplinaridade como base para o ensino e uma formação de professores fragmentada.

Nessa perspectiva de formação fragmentada de professores, é possível sinalizar também a hierarquização entre disciplinas específicas e disciplinas pedagógicas, dentro das quais encontramos os estágios supervisionados para formação de professores, os quais tiveram mudanças significativas a partir de 2002, com a homologação das Diretrizes Curriculares Nacionais para Formação de Professores DCNFP.

De acordo com discursos circulados por documentos da ANFOPE Associação Nacional pela Formação dos Profissionais da Educação (2002; 2004), o processo de elaboração das diretrizes curriculares para os cursos de graduação, desencadeado pelo MEC e pelo CNE em

Olh@res, Guarulhos, v. 1, n1, p. 207-238, maio. 2013. 
1997, esteve inserido no processo de ajuste das universidades às novas exigências dos organismos internacionais, em particular do Banco Mundial e visa adequar a formação de profissionais ao atendimento das demandas de um mercado globalizado.

No campo da formação de professores, o processo de elaboração das diretrizes expressa contradições presentes, trazendo à tona os dilemas e as dicotomias no processo de formação, entre eles: a discussão da formação do professor especialista em contraposição ao professor generalista; a autonomia para que os cursos de licenciatura se organizem com identidade própria e com articulação entre os departamentos e os demais cursos de áreas específicas; bem como o estágio supervisionado desde o início do curso, permeando toda a formação e não sendo restrito somente às disciplinas pedagógicas, entre outros.

O documento das Diretrizes Curriculares Nacionais para a Formação de Professores da Educação Básica, em nível superior, curso de licenciatura, de graduação plena - (PARECER CNE/CP 9/2001) foi aprovado pela CNE em 8/5/2001 e homologada em 2002, abordando desde as competências e habilidades a serem desenvolvidas nos futuros professores, carga horária, avaliação do curso e dos professores até a organização institucional e pedagógica das instituições formadoras.

Com a homologação das Diretrizes Curriculares Nacionais para a Formação de Professores, em 2002, os cursos de licenciatura passam a assumir, em termos curriculares, terminalidade e integralidade própria em relação aos bacharelados, à medida que passam a ser preconizados, para eles, projetos específicos.

Nessa perspectiva, discursos passam a ser engendrados no sentido de exigir currículos próprios para as licenciaturas que não se confundissem com os bacharelados e que se afastassem da antiga concepção de formação de professores, que ficou caracterizada como modelo $3+1$, onde nos três primeiros anos do curso os alunos faziam as disciplinas do bacharelado e, como um apêndice, com mais um ano

Olh@res, Guarulhos, v. 1, n1, p. 207-238, maio. 2013. 
Entre disciplinas pedagógicas e disciplinas específicas: a formação de professores e a questão do estágio supervisionado em um curso de licenciatura integrada

de curso, os alunos concluíam as disciplinas da licenciatura, mais especificamente os estágios supervisionados, o que lhes possibilitavam o acesso ao diploma de licenciados.

Nessa perspectiva, com a homologação das Diretrizes Curriculares Nacionais para a Formação de Professores - DCNFP - (PARECER CNE/CP 9/2001), diversas discussões foram iniciadas e que culminaram, dentre outros pontos, na rediscussão e reformulação dos currículos dos cursos de licenciatura, especialmente no que diz respeito à carga horária mínima para esses cursos, que passam a ser de 2800 horas (PARECER CNE/CP 28/2001), sendo 1800 horas dedicadas às atividades de ensino/aprendizagem, 200 horas para outras formas de atividades de enriquecimento didático, curricular/científico e cultural, 400 horas de atividades práticas que devem acontecer desde o começo do curso, possibilitando ao aluno um contato desde o início do curso com o seu ambiente de trabalho e 400 horas de estágio supervisionado que devem se iniciar a partir da segunda metade do curso.

Com as DCNFP (PARECER CNE/CP 9/2001), buscou-se implementar currículos de formação de professores que possibilitassem uma maior vivência em seu campo de trabalho, com o aumento da carga horária dos estágios supervisionados e a superação de um visão fragmentada de ensino, através da superação da dualidade entre disciplinas pedagógicas e disciplinas específicas, forte marca das licenciaturas da década de 90 .

No entanto, as práticas de formação de professores e seus respectivos estágios supervisionados, após homologação da DCNFP, podem permitir algumas problematizações, dentre elas: até que ponto o aumento da carga horária dos estágios tem significado o afastamento da antiga concepção de formação de professores que ficou caracterizada como modelo $3+1$ e, com ela, a menor diferenciação entre disciplinas específicas e disciplinas pedagógicas, deixando de lado a antiga concepção da licenciatura como algo residual e inferior

Olh@res, Guarulhos, v. 1, n1, p. 207-238, maio. 2013. 
dentro dos muros da universidade, vista muito mais como atividade vocacional e de responsabilidade exclusiva da Faculdade de Educação?

\section{A Licenciatura Integrada em Química/Física da UNICAMP}

Criado pela Deliberação CONSU 10/98, publicada em 28/07/1998, o curso de Licenciatura Integrada em Química/Física, de responsabilidade da Faculdade de Educação e corresponsabilidades do Instituto de Química e Instituto de Física da UNICAMP, teve suas atividades iniciadas em 01/03/1999, após anos de debates e disputas em torno das disciplinas pedagógicas e específicas do currículo desse curso, bem como de sua concepção de integração curricular. (RAMOS, 2012)

O curso foi criado com a intenção de preparar professores de alta qualificação para o trabalho no Ensino Médio, centrado na experiência investigativa e na reflexão acerca dos aspectos políticos e culturais da educação, enfatizando diferentes processos pedagógicos, políticas públicas, as relações educação-sociedade e a construção do conhecimento educacional.

$\mathrm{Na}$ tentativa de estabelecer um ensino voltado mais para a necessidade de integrar conhecimentos de diversas áreas e de formar professores para trabalhar nesse contexto, a estrutura curricular desse curso integra não só os conteúdos da Física e da Química, mas também da Educação, relacionados aos campos da Filosofia da Educação, História da Educação, Psicologia e Ciências Sociais.

A característica fundamental do curso é o de ser um programa específico de formação de professores, com ingresso exclusivo para a licenciatura, que rompe com o modelo de licenciatura enquanto complementação pedagógica dos bacharelados correspondentes, mais conhecido como modelo $3+1$.

Desde sua criação até o ano de 2005, o curso era composto por oito semestres, sendo os quatros primeiros considerados básicos, onde os

Olh@res, Guarulhos, v. 1, n1, p. 207-238, maio. 2013. 
Entre disciplinas pedagógicas e disciplinas específicas: a formação de professores e a questão do estágio supervisionado em um curso de licenciatura integrada

alunos cursavam disciplinas das áreas da Física, Química e Educação, período destinado para o estudante visualizar as múltiplas relações existentes entre essas áreas.

No final do quarto semestre, cabia ao aluno fazer a opção por uma das duas modalidades do curso: Física ou Química. A partir daí, o ensino era mais focalizado na área escolhida, podendo o aluno, após a conclusão da primeira modalidade, pedir reingresso e concluir a outra modalidade, tendo apenas que cursar as disciplinas referentes a esses quatro últimos semestres.

Com os discursos engendrados pelas Diretrizes Curriculares Nacionais para a Formação de Professores (PARECER CNE/CP 9/2001), possibilidades diferentes foram pensadas na compreensão da formação docente através de seu percurso curricular. Mudanças foram sinalizadas e praticadas como forma de constituir outras formas válidas de formação de professores em campos disciplinares específicos.

Até os últimos anos, os cursos de licenciatura, na grande maioria modalidades dos bacharelados, eram configurados por blocos densos e específicos de conteúdos teórico-científicos de cada campo disciplinar e apenas uma complementação pedagógica que cabia à Faculdade de Educação, o que incluía os estágios supervisionados.

Segundo Rosa (2005), mais do que examinar as grades que foram construídas, é muito importante notar nos currículos dos cursos de licenciatura reformulados, um movimento para dissolver o conhecido formato $3+1$ (3 anos de bacharelado +1 ano de complementação pedagógica).

Em consonância com as exigências de carga horária estipulada pelas Diretrizes Curriculares Nacionais para Formação de Professores (PARECER CNE/CP 9/2001), o currículo reformulado desse curso de Licenciatura Integrada em Química/Física passou a ter uma carga horária maior de estágios ministrados tanto na Faculdade de Educação quanto nos institutos; disciplinas voltadas para atividades de enrique-

Olh@res, Guarulhos, v. 1, n1, p. 207-238, maio. 2013. 
cimento didático, curricular/científico e cultural, como as disciplinas de Colóquios (EL103/203/303/403 ${ }^{1}$ ); disciplinas criadas com o intuito dos alunos terem um maior contato com a pesquisa realizada no interior das unidades, como a disciplina Seminários Integrados de Atividades Científicas em Física e Química (EL204).

Além disso, com a reformulação dos currículos dos cursos de licenciatura, tentativas foram feitas de uma maior aproximação e integração entre unidade e institutos através do compartilhamento de algumas disciplinas, como as disciplinas de Projetos Integrados do Ensino de Química (QL701) e Projetos Integrados do Ensino de Física (FL701), ministradas tanto para o curso de Licenciatura em Física, para o curso de Licenciatura em Química e para a Licenciatura Integrada.

Tais disciplinas poderiam significar um menor distanciamento e hierarquização entre disciplinas pedagógicas e disciplinas específicas, ao serem pensadas na perspectiva de integração entre essas diferentes áreas complementares para a formação de professores.

Anteriormente a essa reformulação, os cursos de licenciatura contavam, geralmente, com uma carga horária de estágio supervisionado entre 120 e 255 horas, na forma de disciplinas chamadas de Prática de Ensino de... e Estágio Supervisionado. Após a reformulação, cursos de licenciatura das diferentes universidades, inclusive a Licenciatura Integrada em Química/Física, passaram a contar com 400 horas de estágio supervisionado relacionado com a profissão, que devem ser realizadas a partir da segunda metade do curso, sendo metade da carga horária desses estágios de responsabilidade da Faculdade de Educação, mediante as disciplinas Estágio Supervisionado I (EL774) e Estágio Supervisionado II (EL874), e a outra metade de responsabilidade dos institutos específicos. No Instituto de Química, com as disciplinas Estágio Supervisionado I (QG680) e Estágio Supervisionado II (QG880), e no

1. Todas as disciplinas dos cursos da UNICAMP são denominadas por siglas contendo letras e números.

Olh@res, Guarulhos, v. 1, n1, p. 207-238, maio. 2013. 
Entre disciplinas pedagógicas e disciplinas específicas: a formação de professores e a questão do estágio supervisionado em um curso de licenciatura integrada

Instituto de Física, com as disciplinas Estágio Supervisionado I (F 901) e Estágio Supervisionado II (F 902).

\section{Narrativas e relações de poder-saber}

A narrativa possui várias raízes teóricas. Dentre as diferentes formas de se conceber a pesquisa que se utiliza de narrativas, escolho como inspiração Walter Benjamin (1994).

Para Benjamin (1994), o contar a história através da narrativa possibilita a ressignificação da própria experiência no seu fazer do cotidiano, na relação entre o eu e o outro, nos acontecimentos que nos deixam marcas de experiências vividas e não apenas vivências sem experiências, através de memórias conscientes e inconscientes cheias de significados, sentimentos e sonhos.

O sujeito da experiência, que narra uma história, é um sujeito situado num tempo e espaço. Ao rememorar experiências, trazidas do passado e ressignificadas no presente, esse sujeito está situado historicamente. Quando esse sujeito narra suas experiências, ele permite a ressignificação do passado com o olhar do presente, dando atenção à forma como os acontecimentos foram se anunciando e construindo outras possibilidades e situações. Nessa vertente, torna-se importante enfatizar a potencialidade das narrativas para a pesquisa histórica que busca por rupturas, descontinuidades e brechas que permitam outras problematizações para as questões colocadas.

Além disso, esse sujeito que narra não é um sujeito que existe a priori, ou um sujeito essência. Se ele tem algo para narrar, é porque experienciou situações, sendo, portanto, um sujeito que se constituiu e é constituído pelas relações sociais, práticas discursivas e relações de poder.

As narrativas que aqui serão utilizadas com a perspectiva de se construir outras problematizações para as questões colocadas fazem parte da tese de doutorado intitulada Um estudo genealógico da cons-

Olh@res, Guarulhos, v. 1, n1, p. 207-238, maio. 2013. 
tituição curricular do curso de Licenciatura Integrada em Química/Física da UNICAMP (1995 a 2011) (RAMOS, 2012). A partir das narrativas transcritas e textualizadas de 10 sujeitos, professores da Faculdade de Educação (FE), do Instituto de Química (IQ) e do Instituto de Física (IFGW) da UNICAMP, que participaram da constituição curricular do curso de Licenciatura Integrada em Química/Física, é possível fazer emergir experiências, brechas, rupturas, histórias e, com elas, relações de poder existentes entre as disciplinas e comunidades epistêmicas, ou seja, a disputa existente entre elas por maior poder, maior visibilidade e até maior espaço dentro desse currículo.

$\mathrm{Na}$ perspectiva de trabalhar com as narrativas enquanto potencialidade para a pesquisa genealógica do curso de Licenciatura Integrada em Química/Física, selecionei intencionalmente sujeitos-narradores que fizeram parte das histórias da Licenciatura Integrada, que estavam dispostos a narrar suas experiências e que tinham histórias para contar. Por escolha dos próprios sujeitos, eles serão apresentados através de nomes fictícios.

Danilo - Docente da Faculdade de Educação/UNICAMP desde 1988, é graduado em Ciências Naturais e Matemática, Mestre em Matemática Aplicada e Doutor em Educação - Entrevista realizada em 21/01/2010.

Eliza - Docente da Faculdade de Educação/UNICAMP desde 1984, é graduada em Psicologia, Mestre e Doutora em Educação - Entrevista realizada em 11/12/2009.

Marcelo - Docente do Instituto de Física/UNICAMP desde 1990, é Bacharel em Física, Mestre e Doutor em Física - Entrevista realizada em 02/02/2010.

Márcio - Docente do Instituto de Física/UNICAMP desde 1989, é graduado em Física, Mestre e Doutor em Física - Entrevista realizada em $15 / 12 / 2009$.

Olh@res, Guarulhos, v. 1, n1, p. 207-238, maio. 2013. 
Entre disciplinas pedagógicas e disciplinas específicas: a formação de professores e a questão do estágio supervisionado em um curso de licenciatura integrada

Miriam - Docente da Faculdade de Educação/UNICAMP desde 1999, é graduada em Dança e Pedagogia, Mestre em Educação e Doutora em Artes - Entrevista realizada em 16/12/2009.

Mônica - Docente da Faculdade de Educação/UNICAMP desde 1983, é Licenciada em Física, Mestre em Psicologia e Doutora em Ciências - Entrevista realizada em 30/11/2009.

Paulo - Docente da Faculdade de Educação/UNICAMP desde 1998, é Licenciado em Química, Mestre e Doutor em Educação - Entrevista realizada em 28/01/2010.

Peterson - Docente do Instituto de Física/UNICAMP desde 1992, é graduado em Física, Mestre e Doutor em Física - Entrevista realizada em 30/11/2009.

Ricardo - Docente do Instituto de Química/UNICAMP desde 1977, é Bacharel em Química, Mestre e Doutor em Química - Entrevista realizada em 20/01/2010.

Sérgio - Docente do Instituto de Química/UNICAMP desde 1969, é Licenciado em Química, Mestre e Doutor em Química - Entrevista realizada em 23/11/2009.

O registro das entrevistas aconteceu por meio de gravações em áudio. As entrevistas foram transcritas, textualizadas e antes que fossem analisadas e adensadas no formato de mônadas, suas transcrições foram encaminhadas para os professore(a)s-narradore(a)s para suas leituras e anuências.

Como uma primeira abordagem para convidar os professores a participarem das entrevistas narrativas, em um conversa preliminar, via e-mail, apresentei aos entrevistados minhas questões norteadoras, esclareci os propósitos da pesquisa e a definição de formalidades como autorização, definição da data e local e garantia de sigilo.

Durante as entrevistas, que ocorreram em locais escolhidos pelos próprios entrevistados com a intenção de que os mesmos se sentissem mais confortáveis durante o encontro, fiz interferências apenas quando

Olh@res, Guarulhos, v. 1, n1, p. 207-238, maio. 2013. 
foi conveniente, lançando perguntas que possibilitassem ao narrador dar continuidade à sua fala, sem a utilização de um roteiro préestabelecido para as entrevistas.

Ao narrarem suas experiências durante a constituição desse curso, mais especificamente com relação aos estágios supervisionados e com as disputas entre disciplinas pedagógicas e específicas por espaço nesse currículo, os professores narradores possibilitam emergir discursos, enquanto vozes institucionais que tensionam relações de poder-saber, e levantar indícios e provocações para continuarmos discutindo esses temas. (RAMOS, 2012)

A maior quantidade de professores da Faculdade de Educação deve-se ao fato de poucos professores dos institutos específicos terem se pronunciados favoráveis à realização da entrevista ou o curso e a época em que ele foi constituído não terem significado experiências para esses professores, mas apenas vivências das quais eles não conseguiam se rememorar, mas apenas se lembrar, sem terem quase nada a narrar.

Disputas entre disciplinas pedagógicas e disciplinas específicas e a questão do estágio supervisionado: $O$ caso da Licenciatura Integrada em Química/Física

Conforme colocado anteriormente, com a homologação das DCNFP, diversas discussões foram iniciadas e que culminaram na rediscussão e reformulação dos cursos de licenciatura. A carga horária mínima, que começou a ser de 2800 horas (PARECER CNE/CP 28/2001), passou a contar com mais horas de estágio supervisionado (400 horas) que devem se iniciar a partir da segunda metade do curso.

Historicamente, a responsabilidade pelos cursos de licenciatura da UNICAMP sempre foi atribuída à Faculdade de Educação, que dividia as disciplinas do currículo com os institutos.

No entanto, uma proposta feita pelo Instituto de Estudos da Linguagem (IEL) e apoiada pela grande maioria dos institutos resultou

Olh@res, Guarulhos, v. 1, n1, p. 207-238, maio. 2013. 
Entre disciplinas pedagógicas e disciplinas específicas: a formação de professores e a questão do estágio supervisionado em um curso de licenciatura integrada

na alteração pelo Conselho Universitário, no final de 2003, do Regimento Geral da UNICAMP, de maneira que os institutos interessados poderiam requerer e ter a responsabilidade acadêmica e administrativa sobre suas licenciaturas.

"Existia uma disputa de poder muito grande entre os cursos de humanas e a Faculdade de Educação, relativa às licenciaturas.” (MARCELO - IFGW)

Esse desejo dos institutos tomarem para si a formação de professores não aconteceu por acaso ou simplesmente por um desejo de formação, mas porque "algumas unidades entendiam que a partir do momento que assumissem para si a coordenação dos seus cursos de licenciatura isso significaria verba, vagas... Eles não perceberam que não era bem isso." (MIRIAM - FE)

Durante os anos de 2004 e 2005 foi discutida, por todas as unidades, a reformulação curricular dos seus cursos de licenciatura e uma das maiores mudanças ocorreu na questão dos estágios.

Com a mudança de responsabilidade pelas licenciaturas e com a necessidade de se aumentar o número de horas de estágio para esses cursos, ficou acordado que essa carga horária de estágio ficaria dividida entre a Faculdade de Educação e os institutos, de maneira que, num total de quatro semestres de estágios, dois semestres seriam de responsabilidade da Faculdade de Educação e dois semestres estariam sob a responsabilidade dos institutos, conforme detalhado anteriormente.

"Para as exatas, aquilo não ficava muito claro. No início, minha sensação era de que se não mudasse, seria melhor para nós. Em algum momento surgiu uma ideia muito otimista e romântica, de que com a responsabilidade pelos estágios, os Institutos e Faculdades teriam um maior orgulho, uma maior preocupação com seus cursos de licenciaturas, que seriam "acolhidos" pela instituição." (MARCELO - IFGW)

Olh@res, Guarulhos, v. 1, n1, p. 207-238, maio. 2013. 
Segundo as narrativas de alguns professores, parecia haver uma intenção de que, com o fato dos institutos tomarem para si parte dos estágios, isso forçaria os mesmos a pensarem mais na formação de seus licenciandos e possibilitaria uma integração maior entre os institutos e professores responsáveis pelos estágios.

Nesse sentido, os estágios passaram a ser um dispositivo em estreita conexão com relações de poder que procuravam distribuir as práticas de formação de professores dentro da universidade.

“... o fato de você transferir uma parte dos estágios para as unidades, a ideia é que isso obrigaria as unidades a olharem para aquilo que acontece no ensino e especialmente na escola básica. Com isso talvez pensarem ou repensarem os seus conteúdos, as suas disciplinas que compõem a formação de professores, buscando saber até que ponto essas disciplinas contribuem com a formação de alguém que vai atuar na escola básica. (...)

Talvez tivesse por trás disso também a intenção de que, na medida em que você tem uma alternância, isso obrigaria uma integração maior." (PAULO - FE)

No entanto, o simples fato de ampliar e compartilhar a carga horária dos estágios não significava obrigatoriamente uma integração entre os institutos, sendo necessário um constante relacionamento entre os mesmos para a continuidade e relação entre os diversos estágios.

"Acredito que a tentativa em teoria era boa, de dividir os estágios entre os institutos, mas precisa ver quem é que está administrando essas disciplinas, quem está supervisionando esses estágios para ver como eles estão funcionando, porque é muito fácil você ter uma disciplina que faz um semestre aqui, um semestre ali, mas que continue coisas completamente independentes, porque um não conversa com o outro." (PETERSON - IFGW)

Olh@res, Guarulhos, v. 1, n1, p. 207-238, maio. 2013. 
Entre disciplinas pedagógicas e disciplinas específicas: a formação de professores e a questão do estágio supervisionado em um curso de licenciatura integrada

Além da divisão da carga horária dos estágios entre institutos e Faculdade de Educação, com a reformulação dos currículos dos cursos de licenciatura e exclusão de disciplinas pedagógicas do currículo, específicas para determinada formação, como as Didáticas e as Práticas de Ensino de..., tentativas foram feitas para uma maior aproximação e integração entre a Faculdade de Educação e os institutos através do compartilhamento de algumas disciplinas, como as disciplinas de Projetos Integrados do Ensino de Química (QL701) e Projetos Integrados do Ensino de Física (FL701), ministradas tanto para o curso de Licenciatura em Física, para o curso de Licenciatura em Química e para a Licenciatura Integrada em Química/Física.

Tais compartilhamentos e integrações poderiam significar outra maneira de se pensar a dualidade entre formação específica e formação pedagógica, ainda bastante presente nos cursos de licenciatura.

"A proposta que veio foi de uma disciplina conjunta entre Faculdade de Educação e os institutos. Eu acho também que é uma tentativa dessa aproximação. O ideal seria uma disciplina QFL, reunindo Química, Física e Licenciatura, mas o fato de você ter Química e Física junto com a Faculdade de Educação, você já cria um elo aqui na Faculdade de Educação e, de certo modo, obriga que institutos e faculdade discutam um plano em comum. Foi mais ou menos dentro desse espírito que essas disciplinas foram criadas. " (PAULO - FE)

No entanto, não é tão simples assim pensar em uma disciplina compartilhada por grupos tensionados por comunidades epistêmicas onde cada uma delas possui concepções diferentes de formação de professores. As trocas de experiência e concepções tornam-se necessárias quando dois professores são responsáveis por uma mesma disciplina e, assim como nos projetos integrados, as especificidades devem ser assumidas e trabalhadas.

Olh@res, Guarulhos, v. 1, n1, p. 207-238, maio. 2013. 
De acordo com Lopes (2006), as comunidades epistêmicas são grupos que compartilham concepções, valores e regimes de verdade e que operam nas políticas pela posição que ocupam frente ao conhecimento. Essas comunidades epistêmicas favorecem determinados discursos, determinadas concepções e visões de mundo, determinados conhecimentos e projetos políticos.

$\mathrm{Na}$ medida em que são várias comunidades epistêmicas, não fixas, elas podem influenciar as políticas de diversas maneiras, em nível local, nacional ou global, permitindo explicar não apenas a convergência das políticas, mas também sua heterogeneidade. (LOPES, 2006, p. 147)

Embora possa haver o entendimento dessas comunidades epistêmicas enquanto grupos com estruturas fixas, que padronizam regimes de verdade, é importante salientar que, ao serem constituídas por sujeitos, essas comunidades epistêmicas são grupos que operam, dentro deles próprios, em meio a heterogeneidades, rupturas, embates, relações de poder-saber e rearranjos que envolvem elementos culturais, sociais, econômicos, entre outros.

Nessa perspectiva, no que concerne ao currículo do curso de Licenciatura Integrada em Química/Física, é possível entender o Instituto de Química, o Instituto de Física e a Faculdade de Educação enquanto comunidades epistêmicas, que emergem de relações intrínsecas entre saber e poder, tanto internamente quanto externamente, onde cada uma delas favorece determinados discursos, determinadas crenças e noções de verdade, em nível local, atuando na política de constituição curricular desse curso de licenciatura.

Nesse sentido, a relação dentro dessas comunidades e entre elas ocorre em meio a dissensos, embates, conflitos e relações de poder-saber, onde cada comunidade defende seu ponto de vista, suas crenças, visões, discursos e territórios, por onde perpassa também a discussão e disputa entre as disciplinas pedagógicas e disciplinas específicas nos currículos desses cursos de licenciatura.

$\mathrm{Na}$ própria constituição curricular do curso, se por um lado, na Faculdade de Educação havia a expectativa de que disciplinas específicas fossem criadas para o currículo da Licenciatura Integrada,

Olh@res, Guarulhos, v. 1, n1, p. 207-238, maio. 2013. 
Entre disciplinas pedagógicas e disciplinas específicas: a formação de professores e a questão do estágio supervisionado em um curso de licenciatura integrada

como a disciplina de Problemas no Ensino de Física e Química (EL136) "que não existia, foi criada especificamente para esse curso e a comissão tinha a expectativa que a Química e a Física também pensassem em disciplinas que fossem específicas para este curso." (ELIZA - FE)

Por outro lado, o que era primordial para o Instituto de Química “era que as disciplinas da Licenciatura Integrada fossem as mesmas da Química Tecnológica nos dois anos iniciais de curso básico." (RICARDO - IQ)

Se as relações de poder produzem saberes, é possível observar que essas relações de poder resultaram num determinado currículo diferentemente daquele que havia sido pensado inicialmente, onde as disciplinas pedagógicas e específicas teriam maior relação, não sendo as primeiras vistas apenas como apêndices de um curso de bacharelado.

"Surgiu então, e foi aprovada, a proposta dessa comissão interna de abrir um curso de Química Tecnológica e um de licenciatura chamada de Integrada, calcada na grade curricular do curso tecnológico, nos mesmos moldes do curso de licenciatura diurno já existente e que tem as mesmas disciplinas do curso de bacharelado diurno. A proposta original da Licenciatura Integrada literalmente "foi para o espaço”." (SÉRGIO - IQ)

O pensar específico sobre a formação de professores e em um modelo de currículo onde houvesse uma menor diferenciação entre disciplinas pedagógicas e disciplinas específicas parece ter sido deixado de lado pelo Instituto de Química quando o currículo e disciplinas da Licenciatura Integrada tornam-se, necessariamente, coincidentes com as disciplinas do curso de Química Tecnológica, um bacharelado.

Olh@res, Guarulhos, v. 1, n1, p. 207-238, maio. 2013. 
"Como é que nós pensamos a grade curricular para o curso de Química Tecnológica? Como nós entendíamos que esse curso tinha disciplinas básicas nos primeiros dois anos e que, portanto, não tinha disciplinas de cunho tecnológico, era perfeitamente plausível colocar os alunos dos dois cursos juntos nos dois anos iniciais, desde que a Licenciatura Integrada também tivesse disciplinas básicas nos dois primeiros anos coincidentes com as disciplinas do curso de Química Tecnológica.” (RICARDO - IQ)

As primeiras propostas de currículos mínimos para cursos de licenciatura começaram a se tornar vigentes a partir de 1962, com os pareceres do professor Valnir Chagas, mas foi somente sete anos depois, com a resolução $\mathrm{n}^{\circ}$ 9, de 10 de outubro de 1969, que a formação pedagógica nos currículos dos cursos de licenciatura foi contemplada.

Essa resolução determinou que os currículos mínimos dos cursos que habilitavam professores ao exercício do magistério, em escolas do antigo $2^{\circ}$ grau, abrangessem as disciplinas de conteúdo específico fixadas em cada caso e as seguintes disciplinas pedagógicas: Psicologia da Educação, Didática e Estrutura e Funcionamento de Ensino de $2^{\circ}$ grau.

Além disso, com essa resolução, tornou-se obrigatória a Prática de Ensino das disciplinas que eram objeto de habilitação profissional, sob a forma de estágios.

Segundo a mesma resolução, as disciplinas de cunho pedagógico deveriam ser ministradas em, pelo menos, um oitavo das horas de trabalho fixadas como duração mínima para cada curso de licenciatura.

Esse currículo mínimo, que tratava as disciplinas pedagógicas como apêndices dos cursos de formação de professores, vigorou até 2002, com a homologação das Diretrizes Curriculares Nacionais para a Formação de Professores (PARECER CNE/CP 9/2001).

Olh@res, Guarulhos, v. 1, n1, p. 207-238, maio. 2013. 
Entre disciplinas pedagógicas e disciplinas específicas: a formação de professores e a questão do estágio supervisionado em um curso de licenciatura integrada

Enquanto que nos currículos de formação de professores da década de 90 é a atuação específica que ganha importância, como a atuação do químico, do físico, do biólogo, sendo a licenciatura vista como algo residual e inferior dentro dos muros da universidade, muito mais como atividade vocacional, com a homologação das Diretrizes Curriculares Nacionais para a Formação de Professores, em 2002, os currículos dos cursos de licenciatura passam a assumir integralidade própria em relação aos bacharelados, à medida que passam a ser preconizados, para eles, projetos específicos.

Nessa perspectiva, os currículos passam a ser pensados de forma específica para as licenciaturas, de modo que eles não se confundam com o bacharelado, distanciando-se da antiga concepção de formação de professores que ficou caracterizada como modelo $3+1$, onde nos três primeiros anos do curso os alunos faziam as disciplinas do bacharelado e, como um apêndice, com mais um ano de curso, os alunos concluíam as disciplinas da licenciatura, mais especificamente os estágios, o que lhes possibilitavam o acesso ao diploma de licenciados.

No entanto, mesmo com as mudanças promovidas por essas diretrizes no contexto da UNICAMP, como através do compartilhamento de disciplinas entre a Faculdade de Educação e os institutos e a divisão dos estágios entre Faculdade de Educação e institutos específicos, a separação entre disciplinas pedagógicas e disciplinas específicas e a hierarquização existente entre elas continua sendo palco de embates e relações de poder nos currículos dos cursos de licenciatura, de um modo em geral, bem como na Licenciatura Integrada em Química/Física.

"Saiu uma concepção de licenciatura que tenta, pelo menos, constituir um projeto de licenciatura que rompe com o modelo da racionalidade técnica. Muitos dos aspectos e princípios presentes nessa proposta construída no interior da FE/UNICAMP seriam, posteriormente, contempladas pelas no-

Olh@res, Guarulhos, v. 1, n1, p. 207-238, maio. 2013. 
vas Diretrizes Curriculares Nacionais para as Licenciaturas (MEC). Essas diretrizes acabariam, de certa forma, legitimando alguns pontos de nossa proposta, tais como ter disciplinas pedagógicas ao longo do curso de licenciatura e constituir licenciaturas independente dos bacharelados." (DANILO -FE)

Nas narrativas de alguns professores podemos perceber 0 distanciamento que há entre as disciplinas pedagógicas e específicas na constituição curricular do curso de Licenciatura Integrada em Química/Física. Mesmo com a reformulação curricular dos cursos de licenciatura, que tenta romper com essa separação, estabelece-se um paralelismo entre pedagógico e específico, ao invés de uma integração.

"Com as mudanças dos estágios, após a reformulação dos cursos de licenciatura, onde esses passaram a ser de responsabilidade um semestre da Faculdade de Educação e outro semestre do Instituto de Física, no primeiro ano que isso aconteceu, o coordenador do estágio na Física, Felipe, veio aqui várias vezes conversar comigo. (...) A vida é um pouco diferente dos planos! De início houve algumas tentativas, mas aí não aconteceu, porque realmente é um sufoco. Acredito que uma pergunta que você deve fazer para todos que estão trabalhando com estágio é: "Como trabalhar os estágios de forma integrada entre os institutos?" Acredito ser difícil, porque a integração deveria primeiro ocorrer entre a Faculdade de Educação e todos os institutos e hoje as turmas de estágio são formadas por alunos dos diferentes institutos." (MÔNICA - FE)

O que podemos observar a partir das narrativas dos professores é o quanto o currículo do curso de Licenciatura Integrada em Química/Física foi constituído em meio a relações de poder-saber entre sujeitos, dentro e entre comunidades disciplinares e epistêmicas e o quanto a dificuldade de relação e a hierarquização existente entre

Olh@res, Guarulhos, v. 1, n1, p. 207-238, maio. 2013. 
Entre disciplinas pedagógicas e disciplinas específicas: a formação de professores e a questão do estágio supervisionado em um curso de licenciatura integrada

disciplinas pedagógicas e específicas constituem um problema para esse e outros cursos de licenciatura.

As relações entre disciplinas específicas e pedagógicas pensadas na perspectiva da integração de saberes produzidos por grupos com especificidades diferentes acabam por não acontecer ou, quando acontecem, são permeadas por discursos e ações contrárias e/ou resistentes a essa integração dos saberes.

Além disso, é possível também verificar nas narrativas a hierarquização existente entre as disciplinas pedagógicas e específicas e a menor importância dada para as primeiras até mesmo dentro dos currículos dos cursos de licenciatura.

Essas disciplinas, pelo menos "Mecânica Quântica I", "Eletromagnetismo", de um certo modo são fundamentais na Física, mesmo para um curso de licenciatura. Ainda por outro lado, esse monte de estágios... Será que é realmente necessário? (MÁRCIO - IFGW)

\section{Considerações Finais}

As questões a serem enfrentadas na formação de professores são históricas. Os cursos de licenciatura, em seus moldes tradicionais, tinham como base a formação nos conteúdos das áreas específicas, onde o bacharelado surgia como opção primordial e até mesmo natural, sendo o diploma de licenciatura visto como apêndice, conseguido após mais um ano de curso, onde eram cursadas as disciplinas de Prática de Ensino e Estágio Supervisionado.

Nessa linha de pensamento, é a atuação do físico, do biólogo, do químico, do geógrafo que são vistos como importantes, sendo tido como residual e até mesmo como inferior dentro da própria universidade a atuação do professor de física, de biologia, de química, de geografia, sendo esta caracterizada muito mais uma atividade vocacional.

Olh@res, Guarulhos, v. 1, n1, p. 207-238, maio. 2013. 
Parte dessa visão distorcida da formação dos professores para a educação básica foi resultado da histórica deficiência da estrutura curricular desses cursos, inclusive com as abreviações possíveis para eles, através de licenciaturas curtas e complementação pedagógica, que resultaram também na duvidosa qualidade da formação desses docentes.

Muito embora a licenciatura tenha conseguido constituir-se enquanto um projeto específico com terminalidade própria, após as últimas diretrizes e reformulações de seus currículos, ainda é possível questionar o quanto a construção de uma identidade própria para esses cursos de licenciatura é impedida por esses ainda funcionarem enquanto anexos na organização institucional dos institutos de origem. Além disso, nesses cursos de licenciatura, nos quais se formam especialistas por área de conhecimento ou disciplina, historicamente temos currículos que foram construídos colocando a ênfase nos conteúdos específicos das áreas em detrimento de um trabalho mais próximo aos conteúdos que serão desenvolvidos na educação básica, segmentando o curso em dois polos: o trabalho teórico e as atividades de estágio, como se um polo não dependesse da existência do outro.

Enquanto o primeiro polo supervaloriza os conhecimentos teóricos, desprezando a prática, o segundo polo supervaloriza a prática e o fazer pedagógico, desprezando a dimensão teórica dos conhecimentos. Assim, a estrutura curricular dos cursos de licenciatura construídos enquanto anexos dos bacharelados e que eram predominantes na formação de professores até meados do início desse século, baseava-se em teorias prescritivas e analíticas, deixando os estágios enquanto disciplinas a serem realizadas no último ano do curso, de forma desarticulada com as teorias e com o restante do currículo, nas quais esses conhecimentos eram postos em prática.

Dessa forma, a relação teoria-prática torna-se um dos pontos centrais de discussão das DCNFP, atrelada à aprendizagem por competências. Segundo os documentos, a articulação entre essas duas dimensões, teoria e prática, permite a mobilização de múltiplos recursos pelo pro-

Olh@res, Guarulhos, v. 1, n1, p. 207-238, maio. 2013. 
fessor, seja através dos conhecimentos teóricos adquiridos na relação com a prática, seja através de questões práticas que serão analisadas mediante os conhecimentos teóricos adquiridos.

\begin{abstract}
A aquisição de competências requeridas do professor deverá ocorrer mediante uma ação teórico-prática, ou seja, toda sistematização teórica articulada com o fazer e todo fazer articulado com a reflexão. (...) Cursos de formação em que teoria e prática são abordadas em momentos diversos, com intenções e abordagens desarticuladas, não favorecem esse processo. (PARECER CNE/CP 9/2001, p. 23-24)
\end{abstract}

A relação teoria-prática demanda, para a formação de professores, uma visão mais integrada entre disciplinas específicas e disciplinas pedagógicas nos currículos desses cursos de licenciatura, que resulte em uma formação em que os professores não saibam apenas conteúdos específicos e conteúdos pedagógicos de forma fragmentada, sem relacioná-los.

(...) nas licenciaturas, os conteúdos disciplinares específicos da área são eixos articuladores do currículo, que devem articular grande parte do saber pedagógico necessário ao exercício profissional e estarem constantemente referidos ao ensino da disciplina para as faixas etárias e as etapas correspondentes da educação básica. (PARECER CNE/CP 9/2001, p. 37)

Historicamente, a disciplinarização vem sendo utilizada como forma hegemônica de organização dos currículos dos cursos de formação em nível superior, em decorrência da busca por uma especialização cada vez mais crescente, atrelada à pesquisa, capaz de mobilizar objetivos sociais específicos.

Ao serem propostos os currículos dos cursos de licenciatura resultantes das últimas reformulações desencadeadas pela promulgação das DCNFP, muito embora algumas leituras errôneas tenham sido feitas desses documentos, não se buscou renunciar a todo ensino estruturado e nem relevar a importância das disciplinas na formação, mas sim considerá-las como recursos que ganham sentidos quando pensados em relação e capazes de possibilitar aos futuros professores percursos formativos variados que resultem em atuações diferenciadas.

Olh@res, Guarulhos, v. 1, n1, p. 207-238, maio. 2013. 
Uma vez que a atuação do professor não é a atuação nem do físico, nem do biólogo, nem do químico, nem do geógrafo, mas a atuação de um profissional que usa os conhecimentos das diferentes disciplinas para uma intervenção específica, cabe a matriz curricular desses cursos de licenciatura não ser a mera justaposição de disciplinas pedagógicas e específicas, mas que permita a integração dos mesmos, através de disciplinas diferenciadas.

Para que essa fragmentação entre conteúdos específicos e conteúdos pedagógicos seja superada, segundo as DCNFP, há que ser superado o padrão segundo o qual os conhecimentos específicos são de responsabilidade dos especialistas e de seus institutos e os conhecimentos pedagógicos são de responsabilidade dos pedagogos e da Faculdade de Educação. O ideal, segundo o mesmo documento, seria a formação integrada da equipe de formadores e a ampliação e ressignificação de cada um dos grupos de conhecimento pelo outro, ou seja, maior inserção de professores de disciplinas específicas nas disciplinas pedagógicas e vice-versa. (PARECER CNE/CP 9/2001) Segundo as DNCFP, a organização institucional da formação de professores deverá levar em conta, quando couber, a estreita articulação com institutos, departamentos e cursos de áreas específicas, bem como constituir direção e colegiados próprios, que formulem seus próprios projetos pedagógicos, articulando as unidades acadêmicas envolvidas.

Essa é uma das propostas presentes nas DCNFP e que resultaram em modificações nos currículos reformulados dos cursos de licenciatura. No entanto, embora mais disciplinas pedagógicas tenham sido inseridas nesses novos currículos, que disciplinas relacionadas com a prática tenham sido propostas desde o início dos cursos e que disciplinas pensadas para maior relação teoria-prática tenham sido criadas, há que se perguntar se essa formação ainda não continua sendo fragmentada, no que se refere à relação disciplinas pedagógicas e disciplinas específicas.

Olh@res, Guarulhos, v. 1, n1, p. 207-238, maio. 2013. 
Entre disciplinas pedagógicas e disciplinas específicas: a formação de professores e a questão do estágio supervisionado em um curso de licenciatura integrada

Um dos pontos a serem analisados quando pensamos na fragmentação desses dois campos de saberes está relacionado aos estágios supervisionados, que por muito tempo ficou reduzido a um espaço na matriz curricular fechado em si mesmo e desarticulado do restante do curso.

Nessa perspectiva, esse artigo pretendeu problematizar questões relacionadas ao aumento da carga horária dos estágios supervisionados, em decorrência das Diretrizes Curriculares Nacionais para a Formação de Professores da Educação Básica - DCNFP (PARECER CNE/CP 9/2001), e as possibilidades que esse aumento tem significado para o afastamento da antiga concepção de formação de professores, que ficou caracterizada como modelo $3+1$ e para a menor diferenciação e hierarquização entre disciplinas específicas e disciplinas pedagógicas nos currículos dos cursos de licenciatura.

Se por um lado algumas narrativas de professores nos mostram disposições por parte de alguns deles, tentativas para que relações acontecessem entre diferentes áreas e a importância para a formação dos professores quando há uma relação mais estreita entre disciplinas pedagógicas e disciplinas específicas, por outro lado, a pouca vontade e as relações de poder que permeiam os institutos ao repensarem as suas disciplinas que compõem a formação de professores ou ao buscarem integrações entre seus conteúdos específicos com os conteúdos pedagógicos, engendram discursos a favor de um entendimento em que a formação de professores é apenas de responsabilidade da Faculdade de Educação.

"A ideia em parte foi essa ao se compartilhar os estágios e para que também não ficasse presente aquela ideia de que na formação do professor a escola é apenas uma preocupação da Faculdade de Educação. Talvez tivesse por trás disso também a intenção de que, na medida em que você tem uma alternância, isso obrigaria uma integração maior.” (PAULO - FE)

Olh@res, Guarulhos, v. 1, n1, p. 207-238, maio. 2013. 
De uma forma geral, esse é um problema que perpassa todos os cursos de formação de professores, pois a existência da separação entre as disciplinas pedagógicas e específicas acaba por constituir práticas discursivas que resultam num isolamento entre a teoria e a prática, provocando assim, muitas vezes um processo ambíguo e incoerente.

Esse processo ambíguo acaba por ser transferido também para as disciplinas de estágio supervisionado. Embora tentativas estejam sendo feitas para que haja o compartilhamento tanto da parte específica quando da parte pedagógica, entre institutos e Faculdade de Educação, durante os estágios supervisionados, como algo que poderia possibilitar uma integração maior entre os institutos, além de ser um dispositivo em estreita conexão com relações de poder que procuravam distribuir as práticas de formação de professores dentro da Universidade, existe ainda uma forte marca de racionalidade técnica a respeito das dificuldades de se estabelecer relações entre disciplinas pedagógicas e disciplinas específicas, atribuindo somente para as disciplinas pedagógicas, de responsabilidade da Faculdade de Educação, a formação de professores.

Olh@res, Guarulhos, v. 1, n1, p. 207-238, maio. 2013. 
Entre disciplinas pedagógicas e disciplinas específicas: a formação de professores e a questão do estágio

supervisionado em um curso de licenciatura integrada

\section{Referências Bibliográficas}

BENJAMIN, W. Obras Escolhidas I. Magia e técnica, arte e política. Ensaios sobre literatura e história da cultura. 7 ed. São Paulo: Editora Brasiliense, 1994.

FOUCAULT, M. O sujeito e o poder. In: DREYFUS, Hubert e RABINOW, Paul. Michel Foucault. Uma trajetória filosófica: para além do estruturalismo e da hermenêutica. Rio de janeiro: Forense Universitária, 1995, p. 231-249.

GOODSON, I. Currículo: teoria e história. Petrópolis: Vozes, 1995.

LOPES. A. C. Discursos curriculares na disciplina escolar química. Revista Ciência e Educação, v. 11, n. 2, 2005

Quem defende os PCN para o Ensino Médio? In: LOPES, A. C.; MACEDO, E. (Orgs.) Políticas de currículo em múltiplos contextos. São Paulo: Cortez, 2006. p. 126-158.

Políticas de integração curricular. Rio de Janeiro: EdUERJ, 2008.

e MACEDO, E. A estabilidade do currículo disciplinar: O caso das Ciências. In: LOPES, A. C. e MACEDO, E. (Orgs.). Disciplinas e integração curricular: histórias e políticas. Rio de Janeiro: DP\&A, 2002, p. 73-94.

PARECER CNE/CP 9/2001. Diretrizes Curriculares Nacionais para a Formação de Professores da Educação Básica, em nível superior, curso de licenciatura, de graduação plena. Conselho Nacional de Educação. Ministério da Educação, 2001.

PARECER CNE/CP 28/2001. Conselho Nacional de Educação. Ministério da Educação. 2001.

RAMOS, T. A. Culturas escolares: o lugar da química e os consumos de propostas curriculares para o ensino médio. Dissertação (Mestrado em Educação) - Faculdade de Educação, Campinas: UNICAMP. 2008.

Um estudo genealógico da constituição curricular do curso de Licenciatura Integrada em Química/Física da UNICAMP (1995 a 2011). Tese (Doutorado em Educação) - Faculdade de Educação, Campinas: UNICAMP. 2012. 
ROSA, M. I. P. Relatório de gestão da coordenação de licenciaturas da Faculdade de Educação no período de $\mathbf{0 6 / 2 0 0 4}$ a 04/2005. 2005. Disponível em: www.fe.UNICAMP.br/administracao/documentos/diversos/Licenciaturasrelat_gestao2004-2005.doc Acesso em: 24/06/2008. . Experiências interdisciplinares e formação de professore(a)s de disciplinas escolares: imagens de um currículo-diáspora. Revista ProPosições, v. 18, n. 2 (53) maio/ago. 2007

SANTOMÉ, J. T. Globalização e Interdisciplinaridade: o currículo integrado. Porto Alegre: Editora Artes Médicas Sul Ltda, 1998.

SILVA, T. T. Documentos de Identidade - uma introdução às teorias de currículo. Belo Horizonte: Editora Autêntica. 2003. 